\title{
ANÁLISE MORFOESTRUTURAL E MORFOTECTÔNICA DA BACIA DO RIO CAPIVARI, SUL DE MINAS GERAIS: A NEOTECTÔNICA E AS SUPERFÍCIES GEOMORFOLÓGICAS

\author{
MORPHOSTRUCTURAL AND MORPHOTECTONIC ANALYSIS \\ NEOTECTONIC AND THE GEOMORPHOLOGIC SURFACES
} OF THE RIO CAPIVARI BASIN, SOUTH OF MINAS GERAIS: THE
}

Roberto Marques Neto
Departamento de Geociências. Universidade Federal de Juiz de Fora, Rua José Lourenço Kelmer, s/n - Campus
Universitário, Bairro São Pedro - Juiz de Fora/MG - CEP: 36036-900.

E-mail: roberto.marques@ufjf.edu.br

\begin{abstract}
Archimedes Perez Filho
Departamento de Geografia, Instituto de Geociências, UNICAMP. Rua João Pandiá Calógeras, 51, Cidade Universitária “Zeferino Vaz" - CEP: 13083-870 - Campinas/SP.

E-mail: archi@ige.unicamp.br
\end{abstract}

Informações sobre o Artigo

Data de Recebimento:

05/07/2011

Data de Aprovação:

$05 / 12 / 2013$

Palavras-chave:

Neotectônica; superfícies geomorfológicas; análise estrutural; maciço alcalino.

\section{Keywords:}

neotectonic; geomorphologic surfaces; structural analysis; alkaline massif.

\begin{abstract}
Resumo
O presente artigo tem por objetivo apresentar resultados de análise morfoestrutural e morfotectônica levada a efeito na bacia do rio Capivari, localizada no sul de Minas Gerais, e discutir o contexto tectônico e estrutural em relação aos efeitos da atividade neotectônica e às superfícies geomorfológicas existentes na área. Apresenta a mensuração do perfil longitudinal e do Relação Declividade x Extensão do curso (RDE) para o rio principal, e a extração de lineamentos para fins de compartimentação morfoestrutural da bacia de drenagem. As evidências no relevo e na drenagem de efeitos deformacionais recentes (neotectônicos) sobejam na área de estudo na forma de capturas fluviais, deflexão e migração de canais, encaixamento e retilinidade abusiva da drenagem, soerguimento de planícies de inundação, deslocamento de cristas, falhamentos atingindo depósitos recentes, entre outros.
\end{abstract}

\begin{abstract}
This article has for objective to show results of morphoestructural and morphotectonic analysis in the rio Capivari basin, localizated in the south of Minas Gerais, and to discuss the tectonic and structural context in relationship at neotectonic activity effects and at the geomorphologic surfaces existing in the area. Present the longitudinal profile and the stream-gradient index (slope $\mathrm{x}$ length) mensuration for the principal river, and the extraction of lineaments to morphoestructural compartmentation of drainage basin. The evidences in the relief as well as in the drainage abound in the studied area in the form of fluvial captures, deflection e migration of streams, fitting and abusive rectlinearity of the drainage, elevation of flood flat lands, crest displacement, failures achieving recent deposits, among other things.
\end{abstract}




\section{Introdução}

Os estudos morfoestruturais e morfotectônicos voltados para a abordagem neotectônica tem sido auspiciosos para o entendimento da evolução do relevo em escala regional e local. Uma miríade de evidências morfológicas impressas no relevo e na rede de drenagem indica a atuação de esforços tectônicos recentes, como modificações nos padrões básicos de drenagem, arqueamento de superfícies aplainadas por efeito de soerguimento crustal, afloramentos rochosos em terraços (também por movimentos ascencionais), migração lateral de cursos d'água e abandono de meandros, capturas fluviais (piracy) com formação de shutter ridges, retilinidade exacerbada em cursos d'água tectonicamente controlados, levantamento de planícies aluviais acompanhadas ou não de soterramento de Gleissolos e de outras coberturas sedimentares, assimetria de bacias de drenagem, desnivelamento de superfícies geomorfológicas, entre outros. Tais evidências foram elucidadas por uma série de autores que estudaram a evolução do relevo sob o prisma da neotectônica, e exemplo de Santos (1999), Etchebehere (2000), Magalhães Jr \& Trindade (2004), Hiruma (2007), Marques Neto (2012), entre vários outros.

Nos cinturões móveis da Plataforma Brasileira, o reconhecimento de efeitos deformacionais é mais facilitado em relação ao interior dos domínios cratônicos, ainda que tais terrenos também sejam acometidos por atividade neotectônica. Os esforços tectônicos dificultam a formação de superfícies aplainadas e a preservação de perfis de alteração nos topos, processos estes que demandam relativa estabilidade crustal. É nas faixas móveis que a reativação de antigas falhas pré-cambrianas vem sendo mais efetiva, provocando o desnivelamento de superfícies geomorfológicas cronocorrelatas e a obliteração dos perfis de alteração existentes. A atividade tectônica, entretanto, não é o único agente de desnivelamento topográfico. Nesse sentido, Silva (2009) ressalta o papel da resistência diferencial da litologia a elaborar superfícies estruturais mantidas no mesmo nível altimétrico por influência da estrutura geológica ou desniveladas pela erosão diferencial em rochas desigualmente friáveis, o que tem levado a uma unificação da terminologia em favor da expressão superfície geomorfológica para qualificar os diferentes compartimentos altimétricos do relevo, conforme proposto por Silva (op cit.).

A bacia do rio Capivari, localizada no sul do estado de Minas Gerais, é das mais importantes sub-bacias do rio Verde. A drenagem disseca tanto intrusões alcalinas cretáceo-paleógenas de Itatiaia/Passa Quatro como rochas pré-cambrianas (figura 1), apresentando uma heterogeneidade litotectônica definidora de diferentes níveis altimétricos que conformam diferentes compartimentos geomorfológicos em $308,10 \mathrm{~km}^{2}$ de área. Tais características motivaram a avaliação de aspectos morfoestruturais e morfotectônicos intervenientes na evolução do relevo local e regional, com algumas considerações sobre suas relações entre a atividade neotectônica intraplaca e as superfícies geomorfológicas correspondentes.

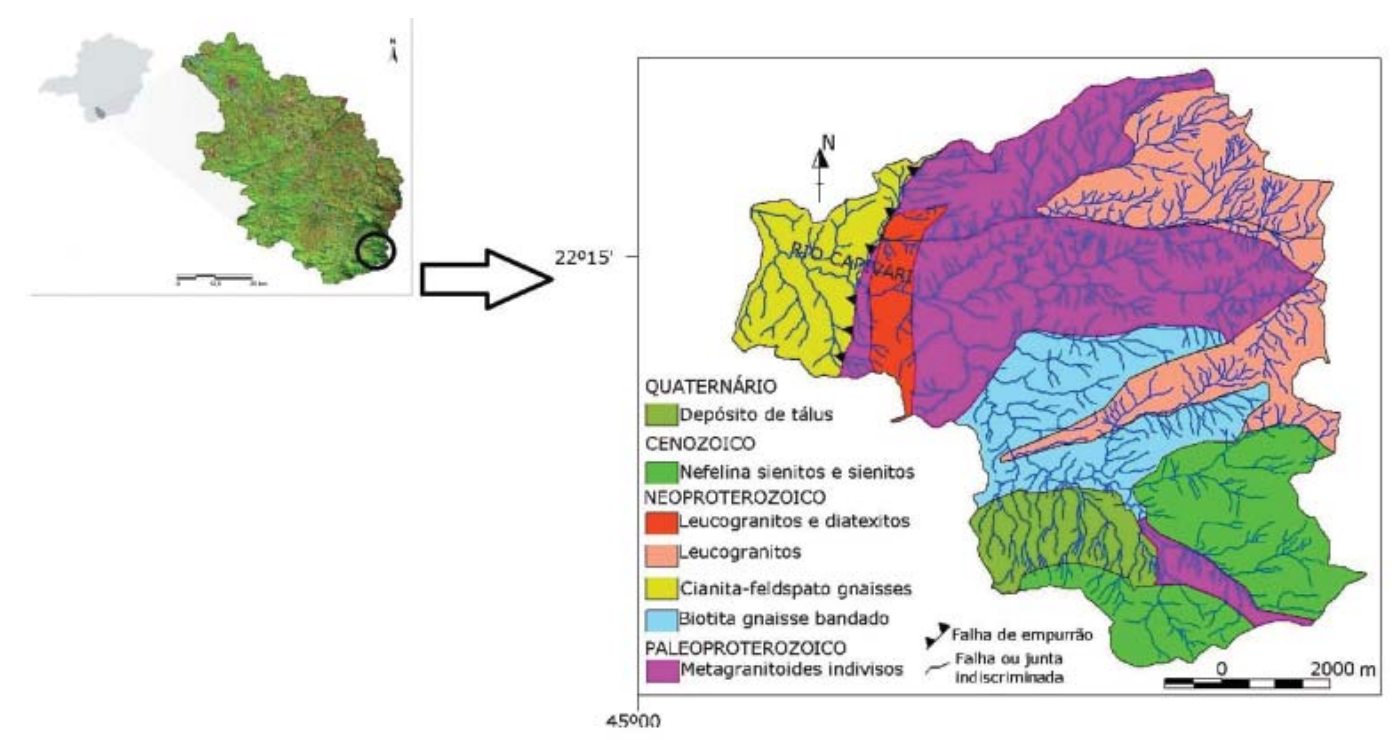

Figura 1 - Localização da bacia do Rio Capivari em referência à bacia do Rio Verde e mapa geológico (adaptado de Trouw ET AL. 2003). 


\section{Procedimentos metodológicos}

A bacia do rio Capivari se posiciona na articulação das folhas Agulhas Negras (SF-23-Z-A-I-4), Passa Quatro (SF-23-Z-A-I-3) e Pouso Alto (SF-23-Z-A-I-1) na escala de $1 / 50000$, sobre as quais foi digitalizada a rede de drenagem em programa Auto Cad.

Como procedimento de análise estrutural mensurou-se o perfil longitudinal do rio Capivari integradamente ao índice "relação declividade/extensão do curso" - RDE - concebido por Hack (1973) e reconhecidamente aplicado nas análises morfoestruturais e morfotectônicas (ETCHEBEHERE, 2000, 2004). Tais mensurações foram levadas a efeito nas próprias cartas topográficas, em escala de 1/50000.

Para a elaboração do perfil foram medidos os comprimentos do vale a cada 20 metros de distância e anotadas suas altitudes, valores estes posteriormente plotados em gráfico de escala aritmética, onde foram interpolados e secionados pela linha de melhor ajuste (BURNNET \& SCHUMM, 1983), que genericamente delimita as áreas de soerguimento acima de seu nível e os compartimentos subsidentes abaixo.

O índice RDE, por seu turno, foi aplicado para os diferentes segmentos definidos pela equidistância das curvas de nível, sendo obtido pela fórmula:

$$
\mathrm{RDE}=(\Delta \mathrm{H} / \Delta \mathrm{L}) . \mathrm{L}
$$

De acordo com a fórmula supramencionada, $\Delta \mathrm{H}$ é a diferença altimétrica entre dois pontos extremos de um segmento ao longo do curso d'água, $\Delta \mathrm{L}$ é a projeção horizontal da extensão do referido segmento e L é o comprimento total do curso d'água a montante do ponto para o qual o RDE foi mensurado.

Também foi executada a extração manual dos lineamentos estruturais representados pelas extensões retilíneas do relevo e da drenagem com base na interpretação de imagens de radar SRTM (Shuttle Radar Topography Mission). As orientações foram representadas em roseta construída em intervalos angulares de $10^{\circ}$, e foram interpretados integradamente ao relevo da bacia para estabelecimento de proposta de compartimentação morfoestrutural, também em escala 1:50000. Os compartimentos identificados foram discutidos no âmbito de sua gênese e evolução morfológica, considerando suas relações com as superfícies geomórficas que conformam e com o quadro neotectônico vigente.

Procurou-se, portanto, articular os dados da análise estrutural e tectônica com as superfícies geomórficas existentes e com os principais processos responsáveis por sua elaboração, tomando como reforço a identificação de níveis topográficos e o cálculo da área e frequência dos topos, procedimentos executados por outros autores interessados no tema (CLARKE, 1966; VARAJÃO, 1991; MAGALHÃES JR. \& TRINDADE, 2004). A posição dos topos na paisagem foi cartograficamente representada na escala 1/50000 juntamente com a rede de drenagem da bacia. No mesmo documento cartográfico foram marcadas com simbologias apropriadas as anomalias de drenagem mais pronunciadas que mantém provável relação com esforços neotectônicos. Foi levada a efeito a interpretação factual da drenagem sobreposta ao mapa de lineamentos, privilegiando-se as anomalias relacionadas às falhas aferidas pelos produtos de sensoriamento remoto e pelo controle em campo.

\section{Aspectos morfoestruturais, superfícies geomorfoló- gicas e neotectônica na bacia do rio Capivari}

As nascentes do rio Capivari estão posicionadas nos terrenos sieníticos do maciço alcalino do Itatiaia. Em seu alto curso, o rio principal se aloja em brecha gnáissicomigmatítica que separa os stocks alcalinos de Itatiaia e Passa Quatro, adaptando-se em falha de orientação SE-NW vinculada à época da intrusão. Perpassa terrenos íngremes de elevada energia em altitudes superiores a 2000 metros até a faixa de 1700 metros, na qual uma suavização do gradiente é assinalada por ruptura no perfil a aproximadamente $4 \mathrm{~km}$ da nascente, quando o rio adentra as áreas formadas por rochas pré-cambrianas. Sucessivos escalonamentos são impostos pelas falhas de borda do maciço alcalino até a afluência do rio das Furnas pela margem direita a 980 metros de altitude, quando se tem a passagem para setores de estocagem sedimentar que se abrem em alvéolos de largura variável até a confluência com o rio Verde nos limites municipais de Itanhandu e Pouso Alto. A partir do contato litológico com as rochas do Complexo Passa Vinte, o gradiente se suaviza e as zonas de acumulação assumem maior expressão. À montante da área urbana observa-se supressão da planície aluvial dada por falha de orientação $\mathrm{NE}\left(40^{\circ}\right)$, quando o rio volta a dissecar as litologias do Grupo Paraíba do Sul.

O perfil longitudinal do rio Capivari segue representado com a linha de melhor ajuste na figura 2. Nota-se que porção expressiva dos terrenos embasados em rochas alcalinas se sobressai acima da linha de melhor ajuste, ficando abaixo desta, sobretudo, as áreas de estocagem sedimentar do médio/baixo curso.

Os resultados obtidos pela aplicação do índice RDE reforçam o que se visualizou no perfil (figura 2). Foram assinalados os pontos de anomalia mais pronunciada por mudanças abruptas numa sequência de resultados ou pelo aparecimento de valores incomuns. O progressivo aumento dos valores indica aumento da energia da corrente, e normalmente estão vinculados a controle tectônico e contatos litológicos determinando encachoeiramentos e segmentos consideravelmente turbulentos.

Na faixa altimétrica situada entre 1760-1660 metros o rio Capivari se aloja na descontinuidade que limita os maciços de Itatiaia e Passa Quatro, penetrando num compartimento de encostas mais suavizadas pela margem esquerda, embasadas por litologia gnáissica. Rupturas de declive são delimitadoras de encostas íngremes pela margem direita, já no maciço monta- 
nhoso alcalino, sendo que na faixa altimétrica de 1400 metros o rio torna a se aproximar do divisor. Uma outra anomalia importante é verificada na faixa dos 1000-980 metros e corresponde à afluência do rio da Colina pela margem direita controlada pelo contato litológico, também verificada pelo perfil longitudinal. A partir dos 940 metros, o gradiente se suaviza e o rio Capivari passa a intercalar planícies alveolares alargadas com trechos de planícies restritas e retilíneas até a foz.

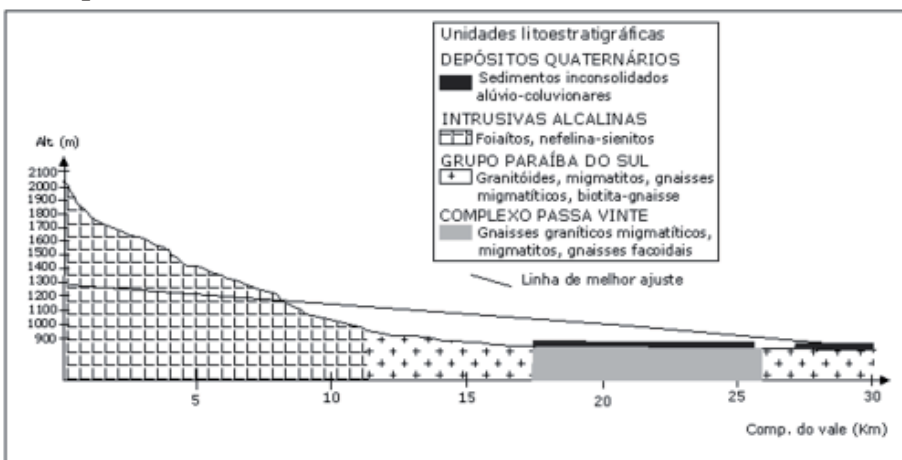

Figura 2 - Perfil longitudinal do rio Capivari.

Ainda que a tabela com os valores de RDE não tenha sido aqui apresentada em função do espaço substancial que ocupa, constatou-se que as anomalias registradas por este procedimento de quantificação ficam bem marcadas nas rupturas do perfil da figura 2, onde podem ser visualizadas. Estas anomalias nem sempre são verificadas em contato litológico, o que aponta para processos diastróficos exercendo falhamentos num mesmo domínio litológico.

A bacia do rio Capivari é pronunciadamente assimétrica, o que se verifica pela substancial diferença mantida entre as áreas das duas margens. Dessa forma, a margem esquerda, de expressão espacial mais restrita, comporta afluentes de curta extensão em padrão subdendrítico a subparalelo. Os principais tributários incidem pela margem direita, entre os quais o rio das Furnas é o mais importante entre os que se dispersam a partir do maciço alcalino do Itatiaia. Tal condição de assimetria pode ser visualizada pelas figuras 1 e 4, nas quais a rede hidrográfica se encontra representada.

A 980 metros de altitude o rio das Furnas aflui no rio Capivari pela margem direita no contato litológico entre as rochas alcalinas e as litologias pré-cambrianas em controle imposto por falha de orientação N-S que desloca a encosta escarpada e intercepta a falha a qual o rio Capivari está adaptado. Em geral, o contato litológico entre as rochas alcalinas e as litologias mais antigas controla as afluências na seção superior da bacia (figura 1), onde os afluentes da margem direita mantém padrão contorcido a subdendrítico e os da margem esquerda paralelo a subparalelo.

$\mathrm{O}$ rígido controle tectônico que engendra migração lateral do rio Capivari faz com que o coletor principal se aproxime da margem esquerda e, por conseguinte, com que o desenvolvimento mais expressivo da rede de drenagem se dê pela margem oposta, onde as sub-bacias apresentam maior expressão areolar. Em contraponto, na outra margem, pequenos cursos d'água apresentam tributação em paralelismo constantemente distanciado e com agudez do ângulo de confluência variável quando estão no maciço alcalino, que é forte controlador do padrão e distribuição da drenagem. Nos terrenos pré-cambrianos um padrão contorcido a subdendrítico ocorre em densidade de drenagem tanto mais baixa quando mais perto da desembocadura.

A análise estrutural levada a efeito conduziu à definição de dois compartimentos morfoestruturais distinguíveis por suas características litotectônicas e geomorfológicas (figura 3).

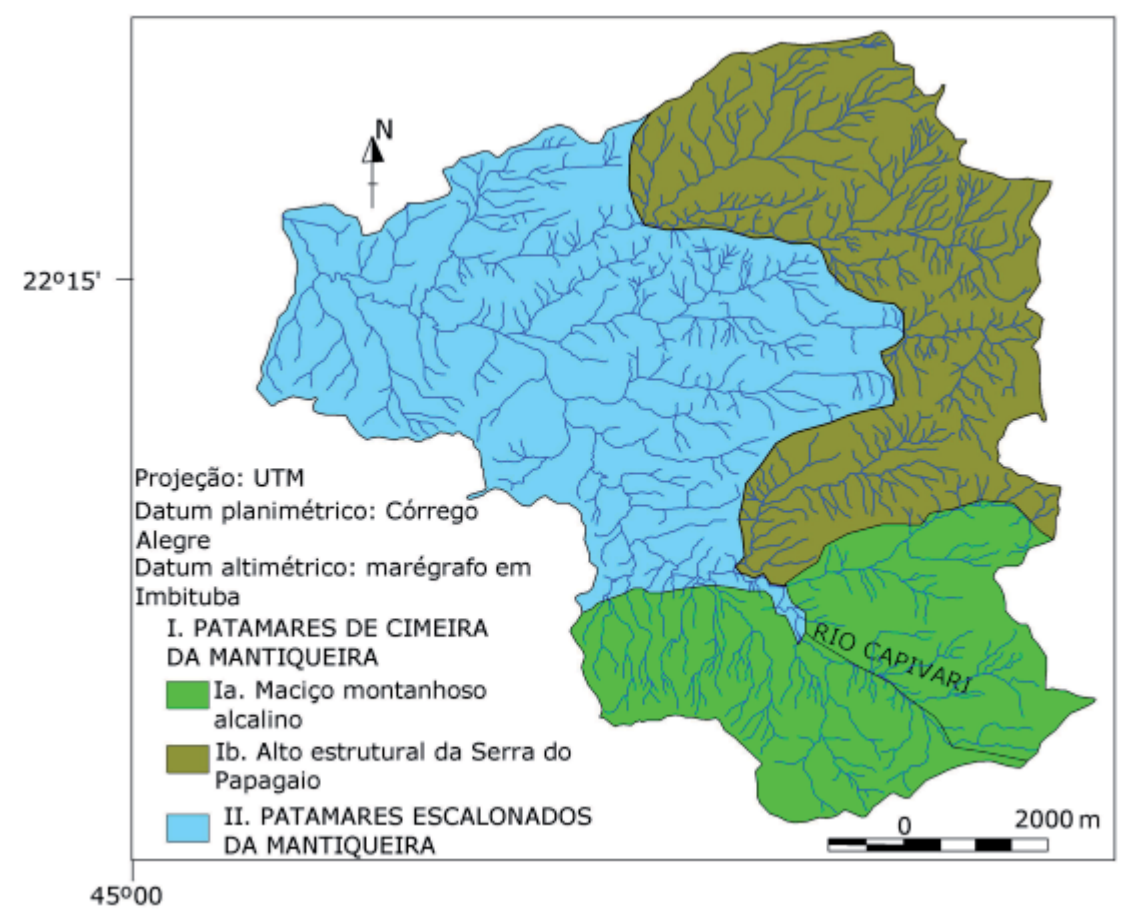

Figura 3 - Compartimentação morfoestrutural da bacia do rio Capivari. 


\section{Compartimento I: Patamares de Cimeira da Man- tiqueira}

Subcompartimento Ia: Maciço Montanhoso Alcalino

Ocupa $26,6 \%$ da área da bacia e ocorre no setor leste vinculado ao domínio das intrusões alcalinas, onde predominam lineamentos de grande extensão com orientação E-W e $\mathrm{NE}-\mathrm{SW}$ (principalmente NE $50^{\circ}$ ) definidos pela drenagem que disseca o setor oeste do batólito, cujo caráter maciço faz diminuir a densidade de lineamentos em relação a outros domínios litológicos na bacia. Acessoriamente ocorrem orientações N-S correspondentes à drenagem em padrão paralelo que aflui no rio Capivari pela margem esquerda. Trata-se de sucessivos degraus em vertentes íngremes e vales encaixados e retilíneos que se sobressaem a formar o compartimento mais elevado de todo o setor oriental da Plataforma Brasileira.

\section{Subcompartimento Ib: Alto Estrutural da Serra do Papagaio}

Esta importante feição morfoestrutural da Serra da Mantiqueira projeta-se na porção NE da bacia em direção S-N até os municípios de Baependi e Aiuruoca, onde estabelece contato abrupto com o embasamento arqueano. Corresponde a um importante alinhamento regional, divisor das bacias dos rios Aiuruoca e Verde que na bacia do rio Capivari mantém a sua extremidade meridional, e que bem pode ser considerado como parte de um compartimento maior representado pelas superfícies cimeiras da Serra da Mantiqueira, com litologia gnáissico-granítica e migmatitos diversos separados pelos sto$c k s$ alcalinos intrusivos. Apresenta uma série de vales estruturais altimontanos, alguns com áreas inundáveis de expressiva extensão e continuidade, como os dos rios Santo Agostinho (Baependi) e Aiuruoca, no município homônimo. tiqueira

Compartimento II: Patamares escalonados da Man-

O compartimento em questão está posicionado na porção oeste da bacia, a partir do contato litológico entre as rochas intrusivas alcalinas e os terrenos metamórficos. Ocorrem alinhamentos de orientação predominante E-W e NE-SW, porém com maior densidade e menor extensão e associados a direções NW-SE. Os traços mais extensos correspondem ao próprio vale do rio Capivari, que de maneira geral perfaz orientação SE-NW com desvios que fazem o ângulo de orientação variar entre os sentidos NW (30-40) e NW (50-60 $)$. Tais desvios são dados por falhas transcorrentes que circunstancialmente determinam processos de captura fluvial com formação de cotovelos (elbow of capture), o que repercute em aspecto contorcido no padrão de drenagem, conforme pode ser detectado pela visualização da figura 4. O compartimento em questão conforma serras de topos estreitos e subnivelados bastante dissecados em contato com as rochas alcalinas que se desmantelam em morros de morfologia convexa na seção inferior da bacia, onde estabelecem rupturas de declive negativas com a planície do rio Capivari. Pela margem esquerda a paisagem é mais recortada, e a individualização de unidades morfológicas de menor expressão espacial em morros, morrotes e pequenas colinas, mais disseminada.

O compartimento II se materializa, dessa forma, após a ruptura de declive que separa a escarpa mais elevada da Serra da Mantiqueira, englobando toda a sua porção interior que se escalona em direção aos contatos tectônicos com os compartimentos planálticos do Sul de Minas. Nesses setores as atividades rurais são mais intensivas e os centros urbanos se instalaram, aproveitando-se, principalmente, das planícies aluviais que passam a aparecer de forma mais copiosa, sobretudo nos setores mais alargados que se formam nos principais depocentros locais.

É possível aventar algumas relações plausíveis entre os compartimentos morfoestruturais e as superfícies geomórficas ocorrentes na área de estudo. Na acepção de Daniels \& Hammer (1992), uma superfície geomórfica pode ser de origem deposicional, erosiva, ou ambas, podendo ocorrer sobre um mesmo tipo de rocha ou truncar litologias diversas; pode ser formada em lapsos temporais relativamente curtos ou apresentar um longo tempo de desenvolvimento, sendo que os efeitos tectônicos, embora deformadores, não chegam a destruir completamente uma superfície.

O subcompartimento Ia conforma alguns topos relativamente extensos preservados pela resistência desigual das rochas alcalinas. Nele foram contados 36 topos, cuja área somada é de $3762,5 \mathrm{~m}^{2}$, o que representa aproximadamente $4,6 \%$ de sua área, com uma densidade de 0,44 topos $/ \mathrm{km}^{2}$ (figura 4). A faixa altimétrica inferior de mapeamento deste subcompartimento está na faixa de 1100-1200 metros, onde se verificam os desnivelamentos topográficos delimitadores. Estão (os topos) distribuídos a partir dos 1200 metros até as proeminências superiores a 2000 metros, com uma concentração maior nos intervalos intermediários entre 1500 e 1800 metros.

Para o subcompartimento Ib, foram anotados 24 topos, e a somatória de sua expressão areolar apontou $2640 \mathrm{~m}^{2}$, valor representativo de $4,55 \%$ da área do compartimento na bacia em densidade de 0,41 topos $/ \mathrm{km}^{2}$. Apresenta superfícies nas cimeiras deformadas e subniveladas pelo arqueamento do bloco, que não impede a manutenção de pisos aplainados com formação de turfeiras e brejos de altitude. Neles a vasta maioria dos topos está acima de 1700 metros, e se sobressaem dois agrupamentos: um entre 1700-1800 metros nos degraus inferiores da borda do maciço, e outro acima de 2000 metros correspondentes aos divisores estreitos com a bacia do rio Aiuruoca, limitados por degrau topográfico indicador de provável soerguimento mais recente que desnivelou o maciço. 
No compartimento II foram contados 81 topos, com área total de $7077,5 \mathrm{~m}^{2}$, o que equivale a $4,2 \%$ do mesmo no perímetro da bacia do rio Capivari e densidade de 0,48 topos/ $\mathrm{km}^{2}$. Na sua porção meio-oeste os topos estão exclusivamente abaixo de 1000 metros, evoluindo acima de 1100 metros à medida que se aproximam das superfícies mais elevadas.

As dimensões, frequência e densidade dos topos são semelhantes nos três compartimentos. Entretanto, há de se considerar que o maciço alcalino e o alto estrutural da Serra do Papagaio ocupam área menor na bacia do Rio Capivari, e somadas não alcançam as dimensões dos patamares escalonados interiores. Assim, os compartimentos Ia e Ib configuram superfícies estruturais em condição de cimeira em função de resistência desigual da litologia somada a processo de soerguimento diferencial. Embora apresentem um número menor de topos, aqueles presentes são mais extensos a indicar relativo aplainamento nas superfícies cimeiras, contrabalançado pelos pulsos ascencionais que vigoram e subnivelam blocos cronocorrelatos em altitudes distintas, conforme apontado por Magalhães Jr \& Trindade (2004). O desnivelamento dos patamares de cimeira da Serra da Mantiqueira reflete provável deformação e soerguimento da Superfície do Japi em mais de um pulso tectônico, conforme aventado por Almeida (1964). No caso do maciço alcalino, o caráter menos friável da litologia também contribui para a diferenciação altimétrica.

Em Passa Quatro foram encontradas bauxitas alumínicas que configuram depósitos de talude geneticamente vinculados ao maciço alcalino homônimo, posicionadas aquém de 1200 metros de altitude. Materiais de origem e constituição similar em outras vertentes do maciço foram datados por Sígolo (1997), que encontrou idade Eocena-Oligocena para os depósitos, o que sinaliza uma suposta relação cronológica com a Superfície do Japi. Embora as coberturas do Paleógeno sejam escassas, alguns materiais datáveis encontrados somados às revisões de literatura e interpretações geomorfológicas favorecem o estabelecimento de uma relação entre as regiões cimeiras da Mantiqueira (topos e altas encostas dos compartimentos Ia e Ib) com as superfícies Sul-Americana de King (1956) ou do Japi (ALMEIDA, 1964), ainda que tectonicamente deformadas, configurando assim superfícies estruturais.

O compartimento II já aponta para uma evolução erosiva mais expressiva perpetrada em litologias mais tenras (predominantemente gnaisses). Apresenta-se em patamares rebaixados que, quanto mais se aproximam da calha do rio Capivari, mais se desmontam em morros e morrotes convexizados e aplainados posicionados entre 900 e 1000 metros de altitude que estabelecem ruptura de declive pronunciada com a planície do rio principal e de afluentes de baixo curso. Infere-se que tais modelados têm gênese erosiva mais recente, de idade quaternária. Em relação a alguma superfície geomorfológica, fica latente um provável vínculo com a Superfície Velhas, cuja idade relativa remete essencialmente ao Quaternário (KING, 1956).

Pela figura 4 pode-se visualizar a distribuição dos topos na bacia do Rio Capivari e o aplainamento consideravelmente restrito em função dos processos ascencionais vigorantes. Ainda assim, algumas cimeiras de declividades mais suaves podem ser identificadas, e que em sua grande maioria partilham de linhas interfluviais internas; os divisores elevados da bacia do Aiuruoca, por sua vez são bastante estreitos. Estes divisores internos de sub-bacias limitam vales adaptados que recorrentemente descrevem retilinidade por considerável extensão por vezes interrompida em desvio abrupto associado ou não a capturas fluviais, tendência esta verificada no mapa, que traz algumas destas evidências marcadas. Tais desvios podem ser relacionados, sobretudo, a falhas transcorrentes, provocando deslocamentos laterais em alinhamentos topográficos acompanhados da formação de baionetas. Em algumas situações, a dissecação horizontal pronunciada aproxima as linhas erosivas apontando situações de captura iminente, algumas francamente consumadas.

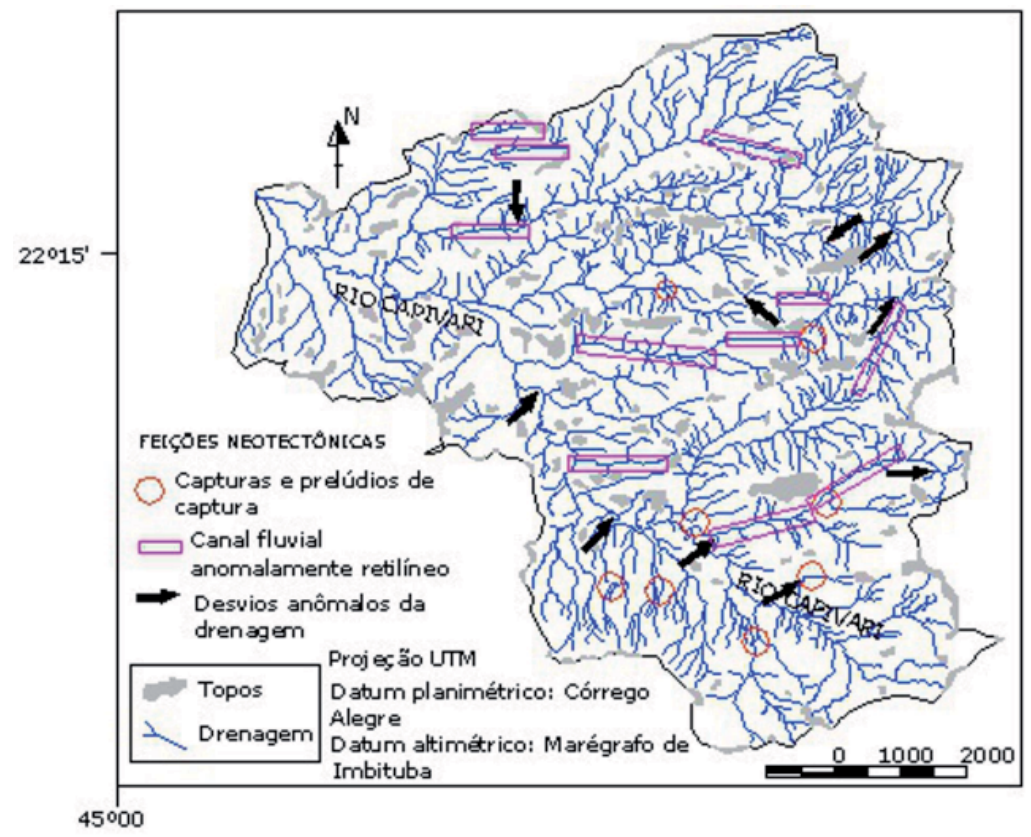

Figura 4 - Posição dos topos na bacia do rio Capivari e principais anomalias de drenagem interpretadas. 
O desnivelamento dos topos tem relação direta com a diferenciação litológica existente na bacia do rio Capivari, que determina diferentes quadros de alteração e friabilidade, repercutindo em rebaixamento mais acelerado em algumas áreas, notadamente na parte oeste, e mais lento em outras, sobretudo na extremidade leste. Além disso, constata-se a presença de patamares de cimeira distribuídos em diferentes níveis altimétricos contidos em um mesmo domínio litológico, desnivelados por processos deformacionais posteriores, como aqueles que escalonaram a Serra da Mantiqueira. Isso oferece subsídio à proposta de Silva (2009) de que a presente temática deve ser discutida em consonância à Teoria da Tectônica de Placas, associando os processos tectônicos ao desenvolvimento de superfícies geomorfológicas, tarefa mais difícil nos domínios intraplaca, áreas estas de maior quiescência tectônica e, portanto, de difícil correlação entre o relevo e tal ordem de processos endógenos (SUMMERFIELD, 1991).

Para a Plataforma Brasileira, circunscrita no interior da Placa Sul Americana, vale a inserção dos efeitos neotectônicos no entrecruzamento dos processos intervenientes na evolução do relevo, uma vez que vem atuando como importantes deformadores de superfícies geomorfológicas ou interferindo diretamente no arranjo e distribuição da rede de drenagem e, em consequência, na preservação/degradação destas superfícies.

\section{Considerações finais}

Em termos de representatividade, a bacia do Rio Capivari revela fortes indícios da dinâmica neotectônica da Serra da Mantiqueira e seus controles no relevo e na rede de drenagem. A este regime se deve, em grande medida, os movimentos ascencionais diferenciais que desnivelam superfícies cronocorrelatas e colocam em parelha altimétrica, muitas vezes, níveis paleotopográficos de idade distinta a partir da reativação de falhas mais antigas. Dessa forma, a reorganização erosiva da drenagem oblitera as superfícies geomórficas e dificulta a preservação de topos aplainados e de testemunhos estratigráficos, consubstanciando-se superfícies estruturais elaboradas principalmente por fatores de ordem litotectônica.

Para estas áreas do Brasil Oriental, onde não se tem razoável estabilidade tectônica para originar extensos níveis aplainados, é interessante a utilização de procedimentos de análise morfoestrutural e morfotectônica como elementos auxiliadores para o estudo da evolução do relevo e das superfícies geomórficas existentes. A apreciação destes e de outros condicionantes, como, por exemplo, a evolução geoquímica da paisagem, tende a ampliar as fronteiras metodológicas da geomorfologia e minimizar os aspectos pouco consensuais existentes na interpretação da evolução do relevo brasileiro e de sua cronologia.

\section{Referências bibliográficas}

ALMEIDA, F. F. M. Geologia do Estado de São Paulo. Boletim $n^{\circ} 41,1964.263 p$.

BURNETT, A. W.; SCHUM, S. A. Alluvial rivers response to neotectonic deformation in Louisiana and Mississipi. Science. v. 222, p. 49-50, 1983.

CHIESSI, C. M. Tectônica Cenozoica no Maciço Alcalino de

Passa Quatro (SP-MG-RJ). 2004. Dissertação (Mestrado em Geologia). Instituto de Geociências, Universidade de São Paulo, São Paulo, 2004.

CLARKE, J. I. Morphometry from maps. In: DURY, G. H. (Ed.) Essays in geomorphology. New York: Elsevier, 1966.

DANIELS, R. B.; HAMMER, R. D. Soil Geomorphology. New York: Wiley \& Sons, inc. 1992.

ETCHEBEHERE, M. L. C. Terraços neoquaternários no vale do Rio do Peixe, Planalto Ocidental Paulista: implicações estratigráficas e tectônicas. Rio Claro, 2000. 264p. Tese (Doutorado em Geociências) - Instituto de Geociências e Ciências Exatas, Universidade Estadual Paulista.

Aplicação do índice "Relação

Declividade-Extensão - RDE" na bacia do Rio do Peixe (SP) para detecção de deformações neotectônicas. Geologia USP-Séries Científicas, São Paulo, v. 4, n. 2, p. 43-56, 2004.

HACK, J. T. Stream-profile analysis and stream-gradient index. Journal of Research of the United States Geological Survey, v. 1, n. 4, p. 421-429, 1973.

HASUI, Y. Neotectônica e aspectos fundamentais da tectônica ressurgente no Brasil. In: $1^{\circ}$ WORKSHOP DE NEOTECTÔNICAE SEDIMENTAÇÃO CONTINENTAL CENOZÓICANO SUDESTE DO BRASIL, 11, 1990, Belo Horizonte. Minas Gerais: Boletim da Sociedade Brasileira de Geologia, 1990. p. 1-31

HIRUMA, S. T. Significado morfotectônico dos planaltos isolados da Bocaina. Tese (Doutorado em Geoquímica e Geotectônica). Instituto de Geociências, Universidade de São Paulo. São Paulo, 2007.

KING, L. C. A Geomorfologia do Brasil Oriental. Revista Brasileira de Geografia. Rio de Janeiro, 18: 147-265, 1956.

MAGALHÃES JR., A. P.; TRINDADE, E. Relações entre níveis (paleo) topográficos e domínios morfotectônicos na região Sul de Minas Gerais: contribuição ao estudo das superfícies erosivas no sudeste brasileiro. Revista Brasileira de Geomorfologia, ano 5, n. 1, p. 01-10, 2004.

MARQUES NETO, R. Estudo evolutivo do sistema morfoclimático e morfotectônico da bacia do Rio Verde (MG), sudeste do Brasil. 2012, 429p. Tese (Doutorado em Geografia), Instituto de Geociências e Ciências Exatas, Universidade Estadual Paulista. Rio Claro, 2012.

SANTOS, M. DOS. Serra da Mantiqueira e Planalto do Alto Rio Grande: a bacia terciária de Aiuruoca e evolução morfotectônica. Rio Claro, 1999. 134p. Tese (Doutorado em Geociências) - Instituto de Geociências e Ciências Exatas, Universidade Estadual Paulista.

SÍGOLO, J. B. Os depósitos de talude de Passa Quatro. In: V SIMPÓSIO DE GEOLOGIA DO SUDESTE, 1997. Anais... Penedo, RJ, v. 1, p. 1-8. SILVA, T. M. Superfícies geomorfológicas no Planalto Sudeste brasileiro: revisão teórico-conceitual. Geo UERJ, v. 3, n. 20, p. 1-22, 2009.

SUMMERFIELD, M. A. Global Geomorphology. New York: John Wiley \& Sons, 1991. 537p.

TROUW, R. A. J; JUNHO, M. C. B; RIBEIRO, A; PACIULLO, F. V. P; AlMeIDA, M. E; VAlERIANO, C. M. Projeto Sul de Minas. Folha Pouso Alto. UFRJ, UFMG, Companhia Mineradora de Minas Gerais, 2003.

VARAJÃO, C. A. C. A questão da correlação das superfícies de erosão do Quadrilátero Ferrífero, Minas Gerais. Revista Brasileira de Geociências, v. 21, n. 2, p. 138-145, 1991. 